\title{
KAJ IAN KESESUAIAN LAHAN BUDIDAYA TAMBAK DI WLAYAH PESSIR KABUPATEN PANGKEP, SULAWESI SELATAN DENGAN APLIKASI SISTEM INFORMASI GEOGRAFIS
}

\author{
Utojo dan Erna Ratnawati
}

Balai Penelitian dan Pengembangan Budidaya Air Payau

Jl. Makmur Dg. Sitakka No. 129, Maros 90512, Sulawesi Selatan

E- mail: litkanta@indosat.net.id

(Naskah diterima: 18 Februari 2013; Disetujui publikasi: 30 September 2013)

\begin{abstract}
ABSTRAK
Penelitian ini memanfaatkan teknologi sistem informasi geografis (SIG) untuk menentukan lahan yang sesuai untuk budidaya tambak di Kabupaten Pangkep, Sulawesi Selatan. Data sekunder yang digunakan berupa data iklim, data pasang surut, peta Rupabumi Indonesia wilayah Pangkep skala 1:50.000, dan peta batimetri skala 1:200.000. Data primer diperoleh dengan metode survai di lokasi penelitian yaitu kualitas air dan tanah tambak. Setiap lokasi pengambilan contoh ditentukan posisi koordinatnya dengan global positioning system (GPS). Data lapangan (fisiko-kimia air dan tanah), data sekunder, dan data citra satelit digital ALOS AVNIR- 2 tersebut dikumpulkan dan dianalisis secara spasial menggunakan SIG. Hasil analisis menunjukkan bahwa tambak yang ada di wilayah pesisir Kabupaten Pangkep mencapai luas 12.199 ha. Dari luas tersebut, yang tergolong berkesesuaian tinggi (22 ha) di Kecamatan Segeri, yang berkesesuaian sedang (6.675 ha), dan rendah (5.502 ha), tersebar di Kecamatan Mandalle, Segeri, Marang, Labakkang, Bungoro, Pangkajene, dan Minasatene, sedangkan yang tidak sesuai (418 ha), tersebar di wilayah pesisir Kecamatan Marang, Labakkang, dan Minasatene.
\end{abstract}

KATA KUNCI: budidaya tambak, kesesuaian Iahan, SIG, Kabupaten Pangkep

ABSTRACT: Land suitability study of brackishwater ponds aquaculture in the coastal area of Pangkep Regency, South Sulawesi with application of geographical information system. By: Utojo and Erna Ratnawati

This research using geographical information system (GIS) technology to determine land suitability for brackishwater pond culture in Pangkep Regency, South Sulawesi. The secondary data used such as climate data, tide data, Indonesian Rupabumi maps of Pangkep area scale of 1:50,000 and bathimetry maps scale of 1:200,000. The primary data (soil and water quality) was found with survey method in research location. Satellite image data of ALOS AVNIR-2, secondary data, and field data (soil and water quality) were integrated and conducted spatial analysis with GIS. The results of analysis show that existing brackishwater pond culture in Pangkep Regency are 12,199 ha. From brackishwater ponds area, which is classified with high suitability (22 ha) in Segeri Subdistrict, moderate $(6,675 \mathrm{ha})$ and low $(5,502 \mathrm{ha})$ distributed in Mandalle, Segeri, Marang, Labakkang, Bungoro, Pangkajene, and Minasatene Subdistricts, and not suitable (418 ha) distributed in Marang, Labakkang, and Minasatene Subdistricts.

KEYWORDS: brackishwater pond culture, land suitability, GIS, Pangkep Regency 


\section{PENDAHULUAN}

Wilayah pesisir merupakan daerah transisi antara ekosistem darat dan laut yang memiliki karakteristik tersendiri dan sifatnya peka terhadap perubahan kondisi lingkungan sekitarnya. Adanya usaha pembukaan tambak berarti wilayah pesisir mengalami tekanan dan proses perubahan kondisi lingkungan yang sangat cepat. Laju perubahan fungsi lahan yang cepat menyebabkan adanya perubahan ekosistem, tipologi pantai, karakteristik, dan daya dukung lahan, serta potensi wilayah pertambakan (Utojo et al., 2009).

Salah satu faktor penting yang menyebabkan rendahnya produktivitas tambak dan tidak berlanjut yaitu kesalahan dalam pemilihan lokasi. Tahapan awal dari pemilihan lokasi berdasarkan atas karakteristik lahan tambak itu sendiri. Data dan informasi mengenai karakteristik lahan dapat menjadi dasar bagi pembudidaya untuk menentukan lokasi yang terbaik, komoditas yang sesuai, pola, teknologi dan musim tanam yang tepat. Pemanfaatan sumberdaya alam pesisir yang melebihi daya dukung alaminya, selain akan merusak lingkungan juga aktivitas budidaya itu sendiri. Untuk mengantisipasi kerusakan dan menjaga kelestarian sumberdaya lahan serta meningkatkan produktivitas tambak, maka pemberdayaan sumberdaya lahan tersebut harus dikelola dan direncanakan sebaik mungkin (Mustafa et al., 2004).

Pemanfaatan dan pengelolaan di wilayah pesisir yang tidak terkendali dengan penataan ruang wilayah yang belum ada batasan dan peruntukannya secara jelas menyebabkan terjadinya degradasi biofisik lingkungan pesisir, konflik pemanfaatan, dan kewenangan penggunaan wilayah pesisir sehingga dapat merusak sumberdaya lahan dan ekosistem pesisir, serta mengurangi efektivitas pengelolaan. Oleh karena itu, dalam pengembangan usaha budidaya tambak harus berhati- hati, terkendali, efektif, ekonomis, dan ramah lingkungan.

Kesesuaian lahan merupakan suatu kunci penting dalam kegiatan akuakultur yang mempengaruhi kesuksesan dan keberlanjutannya (Perez et al., 2003). Kajian kesesuaian lahan budidaya tambak melalui survai, diharapkan dalam pengembangan budidayanya dapat diketahui karakteristik biofisika kimia tanah dan air di lokasi sesuai dengan daya dukung lahannya sehingga mampu meminimasi deg- radasi mutu lingkungan hasil buangan tambak dan kerusakan ekosistem pesisir sebagai habitat sumberdaya perikanan.

Pada umumnya kriteria kesesuaian lahan dapat bervariasi dari satu tempat ke tempat lain, yang penting didasarkan pada faktorfaktor meteorologi, tanah, topografi, dan ketersediaan air, di mana kategori penting dari informasi lingkungan dibutuhkan untuk penilaian kesesuaian lahan (Dennis et al., 2004).

Peningkatan produktivitas tambak yang ramah lingkungan dengan usaha budidaya berkelanjutan sangat bergantung dan ditentukan oleh sistem pengelolaan yang diterapkan, serta memperhatikan potensi pengembangan Iahan budidaya tambak yang sesuai dengan peruntukannya. Luas tambak yang ada di Kabupaten Pangkep sekitar 10.201 ha dengan produksi total 13.098 ton yang didominasi bandeng 10.926 ton, udang windu 1.487 ton, dan udang api-api, serta ikan campuran 686 ton, dirasakan belum dikelola secara optimal sehingga peluang untuk meningkatkan produktivitas tambak masih sangat besar (Anonim, 2009)

Penggunaan teknologi sistem informasi geografis (SIG) yang diintegrasikan dengan data citra satelit ALOS AVNIR- 2, untuk mendapatkan data dan informasi secara cepat, akurat, dan terkini tentang potensi dan kesesuaian lahan budidaya tambak, disajikan dalam bentuk peta tematik. Upaya pemberdayaan sumberdaya lahan, sangat diperlukan informasi mengenai kesesuaian lahan budidaya tambak. Hasil dari penelitian ini diharapkan menjadi masukan bagi pemerintah daerah di Kabupaten Pangkep dalam pengeIolaan wilayah pesisir mengenai batasan dan peruntukan yang jelas untuk lahan pengembangan budidaya tambak.

\section{BAHAN DAN METODE}

Kegiatan penelitian pemetaan kesesuaian lahan budidaya tambak dilaksanakan pada bulan Maret 2010 di wilayah pesisir Kabupaten Pangkep Provinsi Sulawesi Selatan. Lokasi yang disurvai sesuai dengan perencanaan tata ruang wilayah pesisir di daerah tersebut yang ditetapkan sebagai zonasi pengembangan perikanan budidaya tambak (Anonim, 2004).

Pengumpulan data primer didapatkan dari pengamatan langsung di lokasi penelitian, menggunakan metode survai dan didesain dengan aplikasi sistem informasi geografis 
(SIG). Pengamatan dan pengambilan contoh air dan tanah di lapangan berdasarkan titiktitik pengamatan yang representatif atau dapat mewakili wilayah yang disurvai berdasarkan kondisi lahan dan keseragaman Iahan (Duivenbooden, 1995). Setiap titik- titik pengamatan dan pengambilan contoh air dan tanah, ditentukan posisinya dengan alat global positioning system (GPS). Sebaran titik- titik pengamatan di lokasi penelitian disajikan pada Gambar 1.

Peubah yang diamati untuk kesesuaian lahan budidaya tambak meliputi kualitas tanah (tekstur, $\mathrm{pH}_{\mathrm{F}}, \mathrm{pH}_{\mathrm{FOx}}$, potensial redoks, bahan organik, pirit, $\mathrm{Fe}, \mathrm{Al}$, dan $\mathrm{PO}_{4}$ ) dan kualitas air (suhu, salinitas, $\mathrm{pH}$, oksigen terlarut, $\mathrm{NO}_{2}, \mathrm{NH}_{4}$, $\mathrm{NO}_{3}, \mathrm{PO}_{4}$, padatan tersuspensi total, dan bahan organik total), topografi, amplitudo pasut, sumber air tawar/ payau, sumber air laut, fasilitas saluran, jarak dari sumber air, abrasi pantai, dan jalur hijau. Analisis peubah kualitas tanah dilakukan di laboratorium dengan mengikuti petunjuk Menon (1973), Ahern et al. (1998a, 1998b), Sulaeman et al. (2005), dan Agus et al. (2006). Peubah kualitas air seperti salinitas, suhu, $\mathrm{pH}$, dan oksigen terlarut, diukur langsung di lapangan serta peubah kimia dianalisis di laboratorium dengan mengikuti petunjuk Menon (1973), Parsons et al. (1989), APHA (2005), serta Sutrisyani \& Rohani (2009).

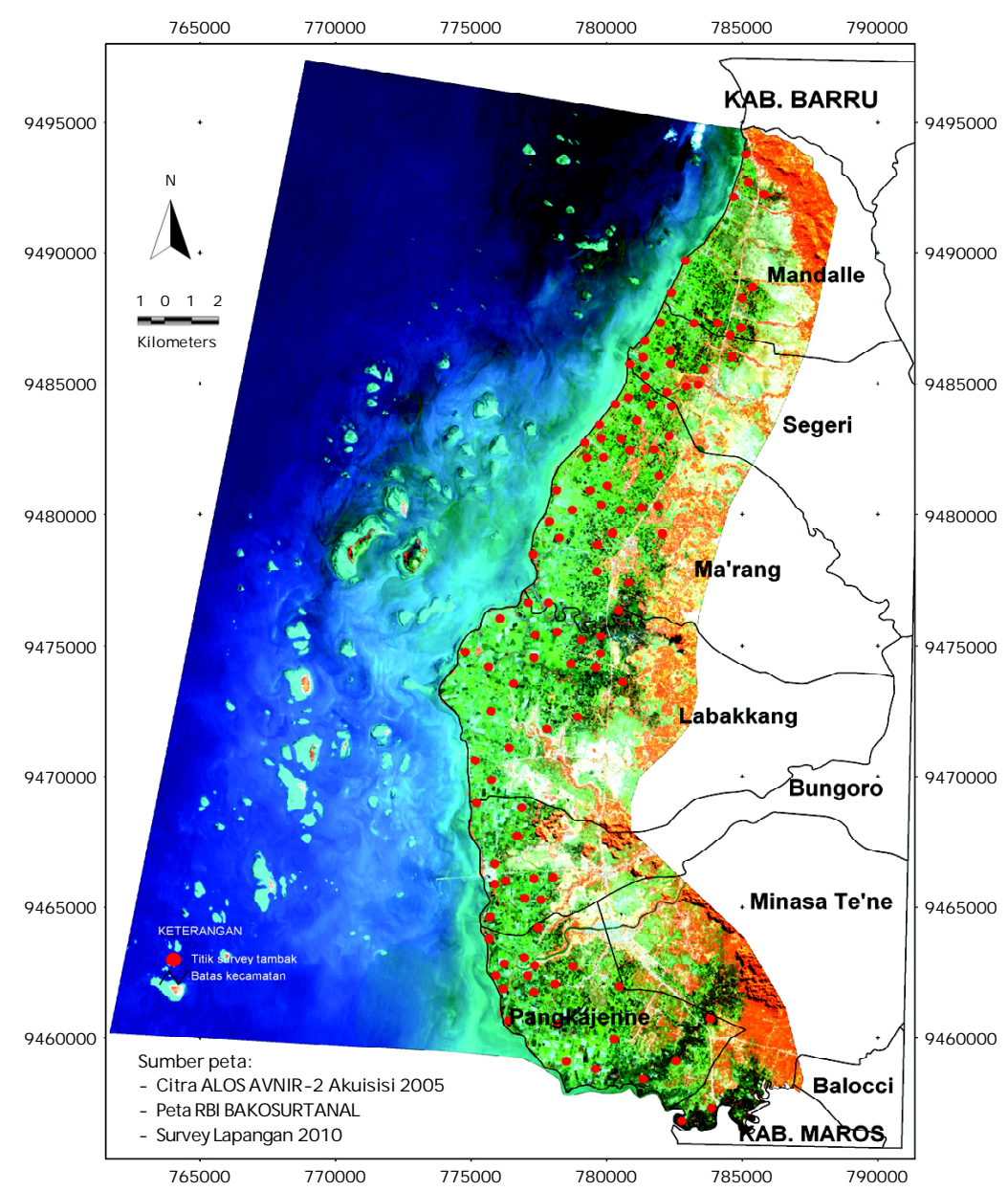

Gambar 1. Peta sebaran stasiun pengamatan kesesuaian lahan budidaya tambak di Kabupaten Pangkep, Sulawesi Selatan

Figure 1. Map of sampling station of brackishwater pond culture land suitability in Pangkep Regency, South Sulawesi 
Data sekunder berupa peta dasar digital lokasi penelitian. Peta dasar berupa peta Rupabumi Indonesia skala 1:50.000, Nomor 2011- 31 (Lembar Pangkajene), 2011- 33 (Lembar Segeri), dan 2011- 22 (Lembar Balang Lompo), keluaran Badan Koordinasi Survai dan Pemetaan Nasional (Bakosurtanal), dan citra landsat ALOS AVNIR- 2 akuisisi 21 Juni 2008.

Peubah-peubah yang digunakan sebagai dasar skala penilaian dan bobot pada kesesuaian lahan budidaya tambak (udang windu dan bandeng) mengacu pada beberapa pustaka (Poernomo, 1992; Boyd, 1995; Karthik et al., 2005).

Menurut Utojo et al. (2009), Iahan budidaya tambak yang masuk kategori kesesuaian tinggi (S1) memiliki nilai skala 4, kategori kesesuaian sedang (S2) memiliki nilai skala 3, kategori kesesuaian rendah (S3) memiliki nilai skala 2, dan kategori tidak sesuai (N) memiliki nilai skala 1. Analisis secara kuantitatif menggunakan pendekatan: $Y=\Sigma$ ai. $X n$, di mana: $Y=$ nilai akhir, ai $=$ faktor pembobot, dan $X n=$ nilai tingkat kesesuaian lahan. Untuk mendapatkan selang nilai pada setiap kategori ditentukan dari nilai persentase sebagai berikut: kategori kesesuaian tinggi (S1): $Y=100 \%$ kategori kesesuaian sedang (S2): $Y=75 \% 99 \%$ kategori kesesuaian rendah (S3): $Y=50 \% 74 \%$ dan kategori tidak sesuai $(\mathrm{N}): \mathrm{Y}=<50 \%$

Pengertian skala penilaian yaitu S1 (kesesuaian tinggi), apabila dalam tingkat pengelolaannya sangat didukung oleh peubah biofisik lahan dan karakteristik lingkungannya, sehingga tingkat produksi yang didapatkan tinggi; S2 (kesesuaian sedang), apabila dalam tingkat pengelolaannya mulai terjadi penurunan peubah biofisik lahan, sehingga untuk mendapatkan tingkat produksi yang tinggi disarankan adanya input teknologi; S3 (kesesuaian rendah), apabila dalam tingkat pengelolaannya disertai dengan penurunan peubah biofisik lahan yang berarti, produksi yang didapatkan rendah sehingga untuk meningkatkan produksi mutlak harus ada input teknologi dan N (tidak sesuai), apabila dalam tingkat pengelolaannya, lahan memiliki faktor pembatas cukup berat sehingga mencegah kemungkinan penggunaannya.

Data sekunder dan primer dikumpulkan, kemudian dianalisis secara spasial dalam SIG (Purwadhi, 1999). Pada proses analisis dalam komputer dengan program ArcView 3.3 dengan cara menginterpolasi yaitu me- masukkan setiap peubah data melalui setiap titik pengamatan menjadi area (polygon). Cara interpolasi titik pengamatan menjadi area menggunakan metode Kriging (Yost et al., 1982). Dari hasil interpolasi setiap peubah data yang didapatkan, disusun dalam bentuk peta tematik. Kemudian dilakukan overlay (tumpang susun) pada setiap peubah data yang tersusun dalam bentuk peta tematik dengan mempertimbangkan pembobotan dan skala penilaian untuk mendapatkan nilai skoring dalam menentukan kesesuaian lahan budidaya tambak yang akurat dan peta terkini untuk prospek peruntukan sumberdaya lahan perikanan pesisir di Kabupaten Pangkep bagi budidaya tambak.

\section{HASIL DAN BAHASAN}

\section{Keadaan Lokasi dan Infrastruktur}

\section{Keadaan Lokasi}

Tahap awal telah dilakukan survai kesesuaian lahan budidaya tambak di tujuh kecamatan wilayah pesisir Kabupaten Pangkep di antaranya Kecamatan Mandalle, Marang, Segeri, Bungoro, Labakkang, Pangkajene, dan Minasatene dengan potensi tambak 13.495 ha dan luas tambak yang ada 10.201 ha. Secara geografis Kabupaten Pangkep memiliki panjang pantai sekitar $95 \mathrm{~km}$, luas wilayah $1.112,29 \mathrm{~km}^{2}$ dan terletak pada koordinat antara 119 $22^{\prime} 12^{\prime \prime}-119^{\circ} 49^{\prime} 14^{\prime \prime}$ Bujur Timur dan 433'36"- 456'24" Lintang Selatan, meliputi 12 kecamatan dan 102 desa/kelurahan. Batas wilayahnya sebelah utara berbatasan dengan Kabupaten Barru, sebelah timur berbatasan dengan Kabupaten Bone, sebelah Selatan berbatasan dengan Kabupaten Maros dan sebelah Barat berbatasan dengan Selat Makassar.

Kabupaten Pangkep terletak di pantai Barat Sulawesi Selatan. Pantainya landai dan perairan lautnya dangkal serta di sekitarnya terdapat Pulau Laiya, Pulau Salemo, Pulau Sabutung, Pulau Saugi, Pulau Podang-podang, dan Pulau Badik. Memiliki tiga sungai besar yaitu Sungai Limbangan, Sungai Pangkajene, dan Sungai Binangasangkara dengan beberapa percabangan anak sungai yang bermuara ke laut. Sungai-sungai tersebut sebagai sumber air utama untuk mengairi pertambakan di sekitarnya. Status lahan pantai saat ini meliputi pertambakan rakyat yang umumnya memiliki bentuk petakan dan saluran 
tambak yang berbeda serta luas tambak yang bervariasi berkisar 0,5-3,0 ha dengan satu pintu, kedalaman tambaknya berkisar 0,75 1,50 m; pematangnya ditumbuhi rumput alangalang, tebal, dan tinggi, terdapat wilayah persawahan pasang surut yang letaknya jauh dari laut sebagian dikonversi menjadi tambak dan tambak yang letaknya dekat dengan laut sebagian besar berasal dari konversi lahan hutan mangrove. Menurut Mustafa et al. (2006), peningkatan luas tambak yang lebih besar terjadi di Kabupaten Pangkep yaitu dari 7.779 ha menjadi 13.528 ha atau terjadi pertambahan 5.749 ha selama sebelas tahun dan terjadi penurunan luas sawah yang ada di kawasan pesisir dari 22.803 ha menjadi 18.280 ha akibat konversi sawah menjadi tambak. Konversi sawah menjadi tambak umumnya terjadi pada sawah- sawah yang berdekatan dengan tambak. Pada umumnya tempat pemukiman pesisir di Kabupaten Pangkep berada di wilayah unit pertambakan. Pemukiman tersebut ada yang padat, sedang, dan relatif sedikit penduduknya. Semakin padat pemukiman, cenderung semakin menurun kualitas lahannya akibat pasokan limbah rumah tangga yang semakin meningkat sehingga dapat menurunkan produktivitas tambak. Umumnya pembudidaya tambak di Kecamatan Mandalle, Marang, dan Labakkang lebih banyak beraktivitas di laut atau usaha yang lain daripada di tambak. Komoditas yang dibudidayakan yaitu udang windu dan bandeng pola monokultur atau polikultur yang dikelola secara tradisional sampai tradisional plus.

Kabupaten Pangkep memiliki daratan yang terdiri atas dataran rendah, berbukit, dan bergunung. Dataran rendah seluas 73- 721 ha, membentang mulai dari garis pantai barat ke timur berupa rawa- rawa, tambak, dan persawahan, yang memiliki ketinggian 0- $2 \mathrm{~m}$ di atas permukaan laut dengan kelerengan $0 \% 2 \%$ sedangkan daerah perbukitan dan pegunungan dengan ketinggian 100- $1.000 \mathrm{~m}$ di atas permukaan laut terletak di sebelah timur berupa batu cadas. Terdapat dua musim yaitu musim kemarau pada bulan April- September dan musim hujan pada bulan OktoberMaret. Curah hujan di dataran rendah sampai ke pantai berkisar 2.000-2.500 mm/tahun (Anonim, 2009). Karakteristik wilayah yang demikian dan ditunjang dengan daya dukung lahan serta iklim yang memadai, cukup potensial untuk pengembangan kegiatan budidaya tambak.
Wilayah pesisir yang ideal untuk usaha budidaya tambak, sebaiknya memiliki persyaratan lokasi tambak yaitu kualitas tanah, kualitas air laut, dan kualitas air tawarnya sesuai untuk teknologi budidaya yang akan diterapkan, tinggi pasang surut air lautnya 1,1-2,1 m; topografi pantainya relatif landai dengan dasar perairan lautnya agak dalam, curah hujan kurang dari $2.000 \mathrm{~mm} /$ tahun, bebas dari banjir, terlindung dari pengaruh arus kuat, gelombang besar, angin kencang, dan bebas cemaran (Ahmad et al., 1996).

\section{Infrastruktur}

Keberadaan fasilitas infrastruktur di wilayah pertambakan Kabupaten Pangkep yaitu dekat dengan jalan raya yang dapat dilalui kendaraan roda empat yang menghubungkan Kabupaten Pangkep dan Kota Makassar, terdapatnya sentra pembenihan udang, pabrik pakan, dan pabrik es, serta pengumpul udang di Pangkep dan Makassar sehingga dapat memudahkan di dalam pengangkutan dan pengadaan benih udang, serta sarana produksi tambak saat operasional budidaya dan produksi udang dari hasil budidaya saat panen hingga pemasaran. Pada umumnya saat panen udang, biasanya pengumpul datang ke lokasi tambak langsung membeli ke pembudidaya, pengumpul tersebut menjual udang ke eksportir di Makassar, kemudian siap untuk diekspor. Di lokasi survai relatif aman dan terdapat kemudahan dalam mendapatkan tenaga kerja baik kuantitas maupun kualitasnya dalam bidang pertambakan.

\section{Kondisi Tanah Pertambakan}

Pada umumnya di semua wilayah kecamatan pesisir Kabupaten Pangkep, jenis tanahnya adalah aluvial dengan kondisi lahan yang relatif seragam. Sepanjang tepi pantai yang berhadapan dengan laut ditumbuhi mangrove yang didominasi jenis Avicennia sp. dan agak jauh dari laut berturut- turut Sonneratia sp., Bruguiera sp., dan Rhizophora sp. dengan lebar jalur hijau berkisar 50-100 m. Wilayah daratan pantai yang agak jauh dari laut berupa lahan kosong atau tegalan yang ditumbuhi tanaman alang- alang dan vegetasi campuran tanaman pantai lainnya. Pada daerah bantaran sungai, vegetasi mangrove didominasi oleh jenis Nypa sp. yang kondisi tanahnya memiliki bahan organik tinggi, $\mathrm{pH}$ rendah, kandungan $\mathrm{Fe}$, dan $\mathrm{Al}$, serta pirit yang tinggi. Lokasi yang demikian kurang potensial untuk kegiatan 
pertambakan dan dinilai memiliki tingkat kesesuaian rendah. Lokasi tambak di sekitar mangrove yang berdekatan dengan laut atau merupakan tambak yang sudah lama beroperasi dinilai memiliki kesesuaian sedang, karena jangkauan air pasang laut yang mudah didapatkan dan proses remediasi sudah berlangsung lama seperti $\mathrm{pH}$ tanah dengan indikasi netral hingga basa, kandungan bahan organik, $\mathrm{Fe}, \mathrm{Al}$, dan pirit sangat rendah.

Sebanyak 133 contoh tanah hasil survai yang didapatkan pada kedalaman 0-0,2 m dan 0,2-0,4 m untuk kesesuaian lahan budidaya tambak di Kabupaten Pangkep, disajikan pada Tabel 1. Hasil analisis tekstur tanah pada kedalaman 0- 0,2 m dan 0,2- 0,4 m cukup bervariasi meliputi lempung berliat, lempung berdebu, lempung berpasir, lempung liat berdebu, pasir berlempung, liat berdebu, lempung, debu, dan liat. Tekstur tanah yang didominasi oleh fraksi liat, didapatkan di lokasi tambak bekas sawah, lahan kosong atau tegalan, sedangkan tekstur tanah yang didominasi oleh fraksi pasir, didapatkan di lokasi tambak bekas mangrove dekat laut. Menurut Poernomo (1992), tekstur tanah tambak yang baik untuk budidaya udang tradisional yaitu lempung liat berpasir, sedangkan tambak semi- intensif dan intensif yaitu lempung liat berpasir hingga lempung berpasir. Pada perencanaan pembuatan unit tambak udang intensif, diperlukan dasar tambak yang kompak dan keras agar dapat menyimpan air saat pelaksanaan budidaya sampai dengan panen (Poernomo, 1989). Apabila tekstur tanah di lokasi tambak dominan pasir atau berkarang, tambak tidak dapat menyimpan air sesuai yang dibutuhkan dalam waktu lama, sehingga udang mengalami stres dan kematian. Lokasi tambak tersebut tidak sesuai untuk kegiatan pertambakan.

Kisaran nilai $\mathrm{pH}_{\mathrm{F}}$ tanah tambak yang didapatkan di lokasi survai pada kedalaman 0- 0,2 m $(5,19-7,75)$ dan pada kedalaman 0,2$0,4 \mathrm{~m}(4,09-7,81)$ relatif sama. Kisaran nilai $\mathrm{pH}_{\mathrm{F}}$ tanah tersebut, didapatkan di tambak yang tanahnya terakumulasi bahan organik dan berpotensi kemasaman. Kisaran nilai $\mathrm{pH}_{\mathrm{Fox}}$ tanah tambak yang didapatkan pada kedalaman 0-0,2 m $(0,21-8,05)$ dan pada kedalaman $0,2-0,4 \mathrm{~m}(0,14-8,27)$. Rendahnya $\mathrm{pH}_{\mathrm{Fox}}$ pada kedalaman 0-0,2 m $(0,21)$ dan kedalaman $0,2-0,4 \mathrm{~m}(0,14)$, didapatkan di lokasi tambak mangrove yang telah direklamasi dengan kandungan piritnya tinggi $(6,56 \% 9,55 \%)$, sedangkan contoh tanah yang didapatkan di lokasi tambak bekas sawah, lahan kosong atau tegalan dengan kandungan pirit yang sangat kecil bahkan sampai tidak terdeteksi, memiliki $\mathrm{pH}_{\text {FOx }}$ berkisar 8,05- 8,27.

Nilai potensial redoks tanah yang didapatkan di lokasi survai pada kedalaman 0-0,2 m berkisar (- 395)- (+ 266) $\mathrm{mV}$ dan kedalaman 0,2$0,4 \mathrm{~m}$ berkisar (- 384)- $(+86) \mathrm{mV}$. Hal ini menunjukkan bahwa tanah tambak di Kabupaten Pangkep dalam kondisi tereduksi dan teroksidasi. Variasi nilai potensial redoks tanah sesuai dengan letak pengambilan contoh di lokasi survai. Menurut Noor (2004), kondisi tanah di dasar tambak yang tergenang (anaerob), laju oksidasi, dan proses dekomposisi bahan organik lebih lambat, tetapi memiliki laju pereduksi sulfur dan besi lebih cepat dari pada di dasar tambak yang kering (aerob). Proses reduksi sulfat terjadi pada potensial redoks $200-300 \mathrm{mV}$, sedangkan reduksi besi terjadi pada potensial redoks 180 $\mathrm{mV}$. Untuk kondisi dasar tambak yang baik diperlukan nilai potensial redoks minimal +50 $\mathrm{mV}$ dengan nilai $\mathrm{pH}$ 6,5-8,5 (Boyd dalam Widigdo, 2003).

Konsentrasi Fe dan Al tanah tambak di lokasi survai pada kedalaman 0- 0,2 m berkisar 0- $4.848,00 \mathrm{mg} / \mathrm{L}$ dan $0-542,50 \mathrm{mg} / \mathrm{L}$, sedangkan pada kedalaman 0,2- 0,4 $\mathrm{m}$ berkisar 0- 4.845,50 mg/ L dan 0-485,00 mg/ L. Kisaran nilai konsentrasi Fe dan Al tanah tersebut masih baik untuk kegiatan budidaya tambak. Konsentrasi Fe dan Al dapat berkurang dengan penjemuran tanah dasar, perendaman dan pembilasan tambak. Penjemuran dan perendaman terjadi pemecahan senyawa pirit yang tidak larut menjadi larut dalam air, sedangkan pembilasan untuk mengurangi konsentrasi Fe dan Al yang mengendap di dasar tambak. Untuk mencegah keracunan Fe dan Al di tambak dengan meningkatkan $\mathrm{pH}$ tanah melalui pengapuran dan pengaturan drainase (Abdurachman \&Suriadikarta, 2000). Tingginya nilai konsentrasi Fe dan Al pada kedalaman 0-0,2 m dan 0,2-0,4 m, didapatkan di lokasi tambak bekas mangrove yang berpirit dengan konsentrasi 6,56\% 9,55\% Di lokasi tambak bekas sawah, lahan kosong atau tegalan yang ditumbuhi alang- alang pada kedalaman 0- 0,2 $\mathrm{m}$ dan 0,2-0,4 m; tidak didapatkan Fe dan Al karena tanahnya tidak mengandung pirit. Tanah sulfat masam adalah tanah atau sedimen yang mengandung pirit $\left(\mathrm{FeS}_{2}\right)$, yang apabila kondisinya kering dapat teroksidasi akan melarutkan $\mathrm{SO}_{4}$ dan $\mathrm{Fe}$, serta terjadi penurunan 
Tabel 1. Kisaran nilai peubah kualitas tanah di tambak Kabupaten Pangkep, Sulawesi Selatan

Table 1. Value range of soil quality variables in brackishwater pond of Pangkep Regency, South Sulawesi

\begin{tabular}{|c|c|c|c|}
\hline $\begin{array}{c}\text { Peubah } \\
\text { Variables }\end{array}$ & $\begin{array}{l}\text { Kedalaman } \\
\text { Depth }(\mathrm{cm})\end{array}$ & $\begin{array}{l}\text { Kisaran nilai } \\
\text { Value range }\end{array}$ & $\begin{array}{l}\text { Nilai ideal } \\
\text { Ideal value }\end{array}$ \\
\hline $\begin{array}{l}\text { Tekstur (Texture) } \\
\text { Pasir (Sand) ) (\%) } \\
\text { Liat (Clay ) (\%) } \\
\text { Debu (Silt ) (\%) }\end{array}$ & $0-0.2$ & $\begin{array}{l}\text { Lempung berliat, lempung } \\
\text { berdebu, liat berdebu, } \\
\text { lempung liat berdebu, lempung } \\
\text { ber-pasir, pasir berlempung, } \\
\text { lempung, debu dan liat (Clay } \\
\text { loam, silty loam, silty clay, } \\
\text { silty clay loam, sandy loam, } \\
\text { loamy sand, loam, and sand) }\end{array}$ & $\begin{array}{l}\text { Lempung liat berpasir } \\
\text { (sandy clay loam ): tambak } \\
\text { tradisional semi-intensif } \\
\text { (traditional-semi intensive } \\
\text { ponds )*; Lempung berpasir } \\
\text { (Sandy loam ): tambak } \\
\text { intensif (intensive pond)* }\end{array}$ \\
\hline $\begin{array}{l}\text { Tekstur (Texture): } \\
\text { Pasir (Sand) ) (\%) } \\
\text { Liat (Clay ) (\%) } \\
\text { Debu (Silt ) (\%) }\end{array}$ & $0.2-0.4$ & $\begin{array}{l}\text { Lempung berdebu, liat ber- } \\
\text { debu, lempung berliat, liat, } \\
\text { lempung liat berdebu, } \\
\text { lempung, lempung berpasir, } \\
\text { debu dan pasir berlempung } \\
\text { (Silty loam, silty clay, clay } \\
\text { loam, clay, silty clay loam, } \\
\text { loam, sandy loam, silt, and } \\
\text { sand ) }\end{array}$ & \\
\hline $\mathrm{pH}_{\mathrm{F}}$ & $\begin{array}{c}0-0.2 \\
0.2-0.4\end{array}$ & $\begin{array}{l}5.19-7.75 \\
4.09-7.81\end{array}$ & $6.5-7.0^{*}$ \\
\hline $\mathrm{pH}_{\mathrm{FOX}}$ & $\begin{array}{c}0-0.2 \\
0.2-0.4\end{array}$ & $\begin{array}{l}0.21-8.05 \\
0.14-8.27\end{array}$ & \\
\hline $\begin{array}{l}\text { Redoks potensial } \\
\text { Redox potential (mV) }\end{array}$ & $\begin{array}{c}0-0.2 \\
0.2-0.4\end{array}$ & $\begin{array}{c}(-395)-(+266) \\
(-384)-(+86)\end{array}$ & Minimum: $+50 \mathrm{mV}^{* *}$ \\
\hline $\mathrm{PO}_{4}(\mathrm{mg} / \mathrm{L})$ & $\begin{array}{c}0-0.2 \\
0.2-0.4\end{array}$ & $\begin{array}{l}5.08-273.69 \\
1.98-329.97\end{array}$ & $\begin{array}{l}>60 \mathrm{mg} / \mathrm{L} \text { : tambak tradisi- } \\
\text { onal (tradisional pond), } \\
\text { tambak intensif kurang } \\
\text { diperlukan (not needed for } \\
\text { intensive pond ) }\end{array}$ \\
\hline $\begin{array}{l}\text { Bahan organik } \\
\text { Organic matter (\%) }\end{array}$ & $\begin{array}{c}0-0.2 \\
0.2-0.4\end{array}$ & $\begin{array}{l}0.31-33.53 \\
0.15-70.58\end{array}$ & $1.7-5.2^{* * * *}$ \\
\hline $\mathrm{Fe}(\mathrm{mg} / \mathrm{L})$ & $\begin{array}{c}0-0.2 \\
0.2-0.4\end{array}$ & $\begin{array}{l}0-4,948.00 \\
0-4,845.50\end{array}$ & $\begin{array}{l}\text { Tergantung kandungan pirit } \\
\text { yang teroksidasi saat kering } \\
\text { (Depend on containing of } \\
\text { pyrite oxydated in dry } \\
\text { condition })^{*}\end{array}$ \\
\hline $\mathrm{Al}(\mathrm{mg} / \mathrm{L})$ & $\begin{array}{c}0-0.2 \\
0.2-0.4\end{array}$ & $\begin{array}{l}0-542.50 \\
0-485.00\end{array}$ & $\begin{array}{l}\text { Tergantung kandungan pirit } \\
\text { yang teroksidasi saat kering } \\
\text { (Depend on containing of } \\
\text { pyrite oxydated in dry } \\
\text { condition )* }\end{array}$ \\
\hline Pirit (Pyrite) (\%) & $\begin{array}{c}0-0.2 \\
0.2-0.4\end{array}$ & $\begin{array}{l}0-6.56 \\
0-9.55\end{array}$ & \\
\hline
\end{tabular}


$\mathrm{pH}$ tanah, yang berdampak pada peningkatan kelarutan Al dan Fe seperti terlihat pada Tabel 1. Menurut Poernomo (1992), rawa pantai di kawasan intertidal yang tertutup oleh vegetasi mangrove, tanahnya mengandung pirit. Apabila untuk pertambakan, setelah selesai konstruksi, dilakukan pengeringan, tanah dasarnya berkemasaman tinggi dengan $\mathrm{pH} 2,5-$ 5,0 dan kemasaman akan meningkat setelah tanah tersebut teroksidasi.

Nilai kandungan fosfat tanah tambak di lokasi survai pada kedalaman 0- 0,2 m berkisar 5,08-273,69 mg/ L dan kedalaman 0,2-0,4 m berkisar 1,98-329,97 mg/ L; tergolong rendah sampai tinggi, namun masih baik digunakan untuk kegiatan budidaya tambak sistem tradisional. Fosfor termasuk unsur esensial untuk berkembangnya produktivitas primer dan penambahan fosfor dapat meningkatkan produksi ikan herbivor di tambak (Boyd, 1995). Ketersediaan fosfat $>60 \mathrm{mg} / \mathrm{L}$ di tambak, tergolong baik untuk kegiatan budidaya sistem tradisional (Karthik et al., 2005).
Nilai kandungan bahan organik tanah tambak di lokasi survai pada kedalaman 0- 0,2 m berkisar 0,31\% 33,53\%dan kedalaman 0,2$0,4 \mathrm{~m}$ berkisar $0,15 \%$ 70,58\% masih baik untuk kegiatan budidaya tambak. Menurut Boyd et al. (2002), bahan organik tanah yang baik untuk budidaya tambak berkisar 1,7\% 5,2\% Kandungan bahan organik tanah yang tinggi, didapatkan di lokasi tambak bekas mangrove dan baik untuk penerapan tambak tradisional. Kandungan bahan organik yang rendah, didapatkan di lokasi tambak bekas sawah, tegalan yang ditumbuhi alang-alang dan baik untuk penerapan tambak intensif.

\section{Sumber Air Pertambakan}

Wilayah pertambakan di Kabupaten Pangkep rata- rata memiliki sumber air yang cukup menunjang untuk kegiatan budidaya tambak, hanya jarak lokasi tambak dengan sumber air laut yang bervariasi, menyebabkan salinitas air di setiap unit pertambakan bervariasi pula (Tabel 2). Unit pertambakan yang

Tabel 2. Kisaran nilai peubah kualitas air di tambak Kabupaten Pangkep, Sulawesi Selatan

Table 2. Value range of water quality variables in brackishwater pond of Pangkep Regency, South Sulawesi

\begin{tabular}{|c|c|c|c|}
\hline $\begin{array}{c}\text { Peubah } \\
\text { Variables }\end{array}$ & $\begin{array}{c}\text { Satuan } \\
\text { Unit }\end{array}$ & $\begin{array}{l}\text { Kisaran nilai } \\
\text { Value range }\end{array}$ & $\begin{array}{l}\text { Nilai ideal } \\
\text { Ideal value }\end{array}$ \\
\hline \multicolumn{4}{|l|}{ Salinitas (Salinity): } \\
\hline - Laut (Sea ) & ppt & $30-54$ & $30-35^{*}$ \\
\hline - Muara sungai (Mouth of river ) & ppt & $21-51$ & $10-20^{*}$ \\
\hline - Tambak (Brackishwater pond) & ppt & $10-25$ & $15-25^{*}$ \\
\hline - Air tanah (Ground water ) & ppt & 3-8 & - \\
\hline Suhu (Temperature) & ${ }^{\circ} \mathrm{C}$ & $25.68-36.85$ & $29-31^{*}$ \\
\hline $\mathrm{pH}$ & - & 7.35-9.98 & $7.0-8.5^{* *}$ \\
\hline Tunggang surut (Tidal range) & $\mathrm{m}$ & 1.25 & - \\
\hline Oksigen terlarut (Dissolved oxygen ) & $\mathrm{mg} / \mathrm{L}$ & $2.01-18.44$ & $4-7^{*}$ \\
\hline $\mathrm{NH}_{4}$ & $\mathrm{mg} / \mathrm{L}$ & $<0.0030-3.6054$ & $0.30^{* *}$ \\
\hline $\mathrm{NO}_{2}$ & $\mathrm{mg} / \mathrm{L}$ & $<0.0008-0.3079$ & $0.25^{*}$ \\
\hline $\mathrm{NO}_{3}$ & $\mathrm{mg} / \mathrm{L}$ & $<0.0015-1.3844$ & $0.008^{* *}$ \\
\hline $\mathrm{PO}_{4}$ & $\mathrm{mg} / \mathrm{L}$ & $0.0029-1.8148$ & $0.015^{* *}$ \\
\hline $\begin{array}{l}\text { Padatan tersuspensi total } \\
\text { Total suspended solids }\end{array}$ & $\mathrm{mg} / \mathrm{L}$ & $2-276$ & - \\
\hline $\begin{array}{l}\text { Bahan organik total } \\
\text { Total organic matter }\end{array}$ & $\mathrm{mg} / \mathrm{L}$ & $1.98-36.55$ & $29.50^{*}$ \\
\hline
\end{tabular}

Sumber (Sources):

*) Poernomo (1992); **) Kementerian Lingkungan Hidup (2004) 
berada di dekat laut, memperoleh sumber air dari laut bersalinitas 30-54 ppt dan muara sungai bersalinitas 21- 51 ppt. Pada umumnya semua unit pertambakan masih terjangkau pasang surut air laut, pertambakan yang letaknya agak jauh dari laut, sumber air berasal dari sungai yang bersalinitas 10- 25 ppt, hanya unit pertambakan yang berjarak minimal $3 \mathrm{~km}$ dari laut, sumber air didapatkan dari air tanah melalui pompa dengan kedalaman mencapai $17 \mathrm{~m}$ dan bersalinitas 3- $8 \mathrm{ppt}$, terutama yang banyak dijumpai di Kecamatan Marang dan Segeri.

Selat Makassar merupakan perairan terbuka, umumnya dangkal dan landai, kondisi perairannya relatif jernih, terdapat tiga sungai besar antara lain Sungai Binangasangkara, Sungai Pangkajene, dan Sungai Limbangan yang lebarnya 10-30 m dengan kedalaman 1- 3 $\mathrm{m}$, serta air tanah dengan kedalaman sampai $17 \mathrm{~m}$. Saat ini, perairan tersebut digunakan sebagai sumber pemasok utama unit pertambakan di wilayah pesisir bagian Barat Kabupaten Pangkep.

Pasang surut di wilayah pesisir Kabupaten Pangkep memiliki tunggang pasang sekitar $1,25 \mathrm{~m}$. Kondisi pasang surut yang demikian, memengaruhi kualitas lingkungan perairan budidaya tambak. Tinggi permukaan air selama pasang tinggi dipengaruhi oleh frekuensi amplitudo pasang, kontur tanah, dan elevasi. Pada umumnya wilayah yang dekat pantai memiliki elevasi 0- $2 \mathrm{~m}$, kondisi yang demikian secara gravitasi, baik untuk lokasi tambak yaitu dapat dikeringkan dengan tuntas saat pembangunan tambak, persiapan tambak, panen, dan saat pelaksanaan tambak mudah dalam pergantian air dengan debit yang memadai. Menurut Poernomo (1992), pelaksanaan budidaya tambak dengan pergantian air secara gravitasi saat pasang, lokasi dengan elevasi sedang dan dapat diairi saat pasang tinggi, serta dapat dikeringkan saat surut terendah merupakan lokasi yang ideal untuk pembangunan unit tambak.

Nilai suhu air yang didapatkan di lokasi survai yaitu di tambak udang yang sedang aktif dengan kedalaman 0,5-0,75 m berkisar $25,68^{\circ} \mathrm{C}-36,85^{\circ} \mathrm{C}$. Tingginya nilai suhu tersebut didapatkan di pertambakan tradisional yang relatif dangkal, kisaran nilai suhu tersebut masih baik untuk kegiatan budidaya tambak. Menurut Poernomo (1992), suhu air optimum tambak udang berkisar $29^{\circ} \mathrm{C}-31^{\circ} \mathrm{C}$, kecepatan, dan besarnya konsumsi oksigen meningkat pada suhu yang lebih tinggi, serta udang tumbuh pesat pada suhu $30^{\circ} \mathrm{C}-31^{\circ} \mathrm{C}$.

Nilai pH air yang didapatkan di lokasi survai berkisar 7,35-9,98. Kisaran nilai pH tambak tersebut netral hingga alkalis dan masih baik sebagai media budidaya tambak udang. Tambak yang sudah lama beroperasi, umumnya pH air berkisar 7,5- 8,5; sedangkan tambak baru di kawasan mangrove yang belum direklamasi, $\mathrm{pH}$ - nya sangat rendah yaitu di bawah lima. Pengaruh langsung $\mathrm{pH}$ yang rendah yaitu udang menjadi keropos dan selalu lembek karena tidak dapat membentuk kulit baru, pH yang tinggi menyebabkan peningkatan kandungan amonia yang membahayakan kehidupan udang. Nilai $\mathrm{pH}$ air optimum tambak udang berkisar 8,0- 8,5 (Poernomo, 1992).

Nilai kandungan oksigen terlarut di lokasi survai berkisar 2,01-18,44 mg/ L. Kisaran nilai kandungan oksigen terlarut tersebut masih baik untuk kegiatan budidaya tambak. Rendah dan tingginya nilai kandungan oksigen terlarut, didapatkan di pertambakan tradisional yang airnya relatif dangkal dan banyak tanaman air terutama jenis Hydrilla verticulata, menyebabkan oksigen sangat berfluktuatif pada pagi dan sore hari. Kandungan oksigen terlarut yang rendah atau tinggi dapat menghambat pertumbuhan dan menyebabkan kematian udang. Jika kandungan oksigen terlarut 2,1 $\mathrm{mg} / \mathrm{L}$ pada suhu $30^{\circ} \mathrm{C}$, udang sudah mulai menunjukkan gejala abnormal yaitu berenang di permukaan tambak (Poernomo, 1988).

Kisaran nilai kandungan $\mathrm{NH}_{4}$ di lokasi survai yaitu $<0,0030-3,6054 \mathrm{mg} / \mathrm{L}$ dan masih baik untuk kegiatan budidaya tambak. Kandungan $\mathrm{NH}_{4}$ air optimum tambak udang yaitu 0,25 $\mathrm{mg} / \mathrm{L}$ (Poernomo, 1992). Tingginya kandungan $\mathrm{NH}_{4}(3,6054 \mathrm{mg} / \mathrm{L})$, didapatkan di tambak udang yang telah dipanen dan di tambak tradisional yang dangkal dan banyak klekap yang mati. Amonia dalam bentuk molekul $\left(\mathrm{NH}_{3}\right)$ lebih beracun daripada dalam bentuk ion $\left(\mathrm{NH}_{4}+\right)$, daya racun amonia meningkat seiring dengan meningkatnya $\mathrm{pH}$, suhu, dan salinitas dengan kesadahan air tambak yang rendah. Menurut Effendi (2003), sebagian besar biota akuatik sensitif terhadap perubahan $\mathrm{pH}$ dan menyukai nilai $\mathrm{pH} 7,0$ - 8,5; serta pada $\mathrm{pH} 4,5$ 5,5 dapat menghambat proses nitrifikasi.

Kandungan nitrit $\left(\mathrm{NO}_{2}\right)$ merupakan produk dari proses nitrifikasi yang beracun terhadap ikan dan udang. Nilai kandungan $\mathrm{NO}_{2}$ di lokasi survai berkisar < 0,0008- 0,3079 mg/ L. Kisaran nilai tersebut masih baik untuk kegiatan 
budidaya tambak. Nilai kandungan $\mathrm{NO}_{2}$ yang tinggi $(0,3079 \mathrm{mg} / \mathrm{L})$ didapatkan di tambak baru bekas mangrove dan rumput liar. Kandungan $\mathrm{NO}_{2}$ air optimum tambak udang yaitu 0,25 mg/ L (Poernomo, 1992).

Nitrat $\left(\mathrm{NO}_{3}\right)$ merupakan produk akhir dari proses nitrifikasi sebagai sumber unsur $\mathrm{N}$ esensial bagi pertumbuhan fitoplankton dan tanaman air. Nilai kandungan $\mathrm{NO}_{3}$ di lokasi survai berkisar < 0,0015- 1,3844 mg/ L. Kisaran nilai tersebut masih baik untuk kegiatan budidaya tambak. Kandungan $\mathrm{NO}_{3}$ yang tinggi didapatkan di tambak bandeng dan udang tradisional, serta banyak fitoplankton, tanaman air, dan klekap. Menurut Effendi (2003), kandungan nitrat yang lebih dari $0,2 \mathrm{mg} / \mathrm{L}$ dapat mengakibatkan terjadinya eutrofikasi perairan.

Kandungan fosfat $\left(\mathrm{PO}_{4}\right)$ dalam bentuk anorganik, sebagai sumber unsur $\mathrm{P}$ dan esensial bagi pertumbuhan tanaman air, klekap, plankton, dan lumut di tambak. Kandungan $\mathrm{PO}_{4}$ di lokasi survai berkisar 0,0029- 1,8148 mg/ L. Kisaran nilai tersebut masih baik untuk kegiatan budidaya tambak. Kandungan $\mathrm{PO}_{4}$ yang tinggi $(1,8148 \mathrm{mg} / \mathrm{L})$ didapatkan di tambak bandeng dan udang tradisional serta banyak fitoplankton, tanaman air, dan klekap. Kandungan fosfat pada perairan alami berkisar 0,005- 0,020 mg/ L; sedangkan pada air tanah biasanya sekitar $0,02 \mathrm{mg} / \mathrm{L}$ dan jarang melebihi dari 1 mg/ L (Boyd, 1988).

Kandungan bahan organik total di lokasi survai berkisar 1,98- 36,55 mg/ L dan padatan tersuspensi total berkisar 2-276 mg/ L. Kisaran nilai kandungan bahan organik total dan padatan tersuspensi total yang didapatkan, masih baik untuk kegiatan budidaya tambak. Tingginya nilai kekeruhan akibat lumpur halus, didapatkan di tambak dekat muara sungai. Menurut Reid (1961), perairan dengan kandungan bahan organik total di atas $26 \mathrm{mg} / \mathrm{L}$ adalah tergolong subur. Kondisi tambak yang demikian, baik untuk penerapan tambak tradisional, sedangkan untuk tambak intensif dapat menurunkan kualitas air.

\section{Kesesuaian Lahan Budidaya Tambak}

Dari hasil skoring dan pembobotan biofisik lahan, analisis kualitas tanah dan air, curah hujan, didukung oleh kondisi lokasi penelitian dan status peruntukan lahan, aspek jalur hijau, infrastruktur, dan aspek penunjang lainnya, maka tingkat kesesuaian lahan untuk budi- daya tambak dapat diidentifikasi dan disajikan dalam bentuk peta tematik (Gambar 2). Tambak yang ada di wilayah pesisir Kabupaten Pangkep seluas 12.199 ha. Lahan budidaya tambak berkesesuaian tinggi (22 ha) terdapat di Kecamatan Segeri, sedang (6.675 ha) dan rendah (5.502 ha) tersebar di Kecamatan Mandalle, Segeri, Marang, Labakkang, Bungoro, dan Pangkajene, yang tidak sesuai (418 ha) tersebar di wilayah pesisir Kecamatan Marang, Labakkang, dan Minasatene.

Lebar jalur hijau di sepanjang pantai Kabupaten Pangkep yang harus diaplikasikan minimal 130 kali nilai rata- rata perbedaan air tertinggi dan terendah setempat $(1,25 \mathrm{~m})$ yang diukur dari garis pantai saat air surut terendah yaitu $162,5 \mathrm{~m}$ dan lebar jalur hijau di tepi sungai minimal berjarak $100 \mathrm{~m}$ dari kiri dan kanan sungai besar, serta $50 \mathrm{~m}$ dari kiri dan kanan sungai kecil yang berada di luar pemukiman.

Lahan dengan kesesuaian tinggi dialokasikan untuk kegiatan budidaya udang semiintensif hingga intensif, kesesuaian sedang untuk kegiatan budidaya udang (monokultur) atau udang dan bandeng (polikultur) tradisional hingga tradisional plus, dan kesesuaian rendah untuk kegiatan budidaya bandeng (monokultur) atau bandeng dan rumput laut (polikultur) tradisional.

\section{KESIMPULAN}

Tambak yang ada di wilayah pesisir Kabupaten Pangkep seluas 12.199 ha. Dari luas tersebut, yang tergolong berkesesuaian tinggi (22 ha) di Kecamatan Segeri, yang berkesesuaian sedang (6.675 ha) dan rendah (5.502 ha), tersebar di Kecamatan Mandalle, Segeri, Marang, Labakkang, Bungoro, Pangkajene, dan Minasatene, sedangkan yang tidak sesuai (418 ha) tersebar di wilayah pesisir Kecamatan Marang, Labakkang, dan Minasatene.

\section{UCAPAN TERIMA KASIH}

Terima kasih diucapkan kepada Muhammad Arnold, Haking Made, dan Darsono atas bantuannya dalam pengambilan contoh tanah dan air di lapangan dan Rosiana Sabang, Kamariah, Rahmiyah, dan Rismawati atas bantuannya dalam analisis tanah di laboratorium. Juga diucapkan terima kasih kepada Sutrisyani, Sitti Rohani, Andi Sahrijanna, dan Kurniah atas bantuannya dalam analisis air di laboratorium. 


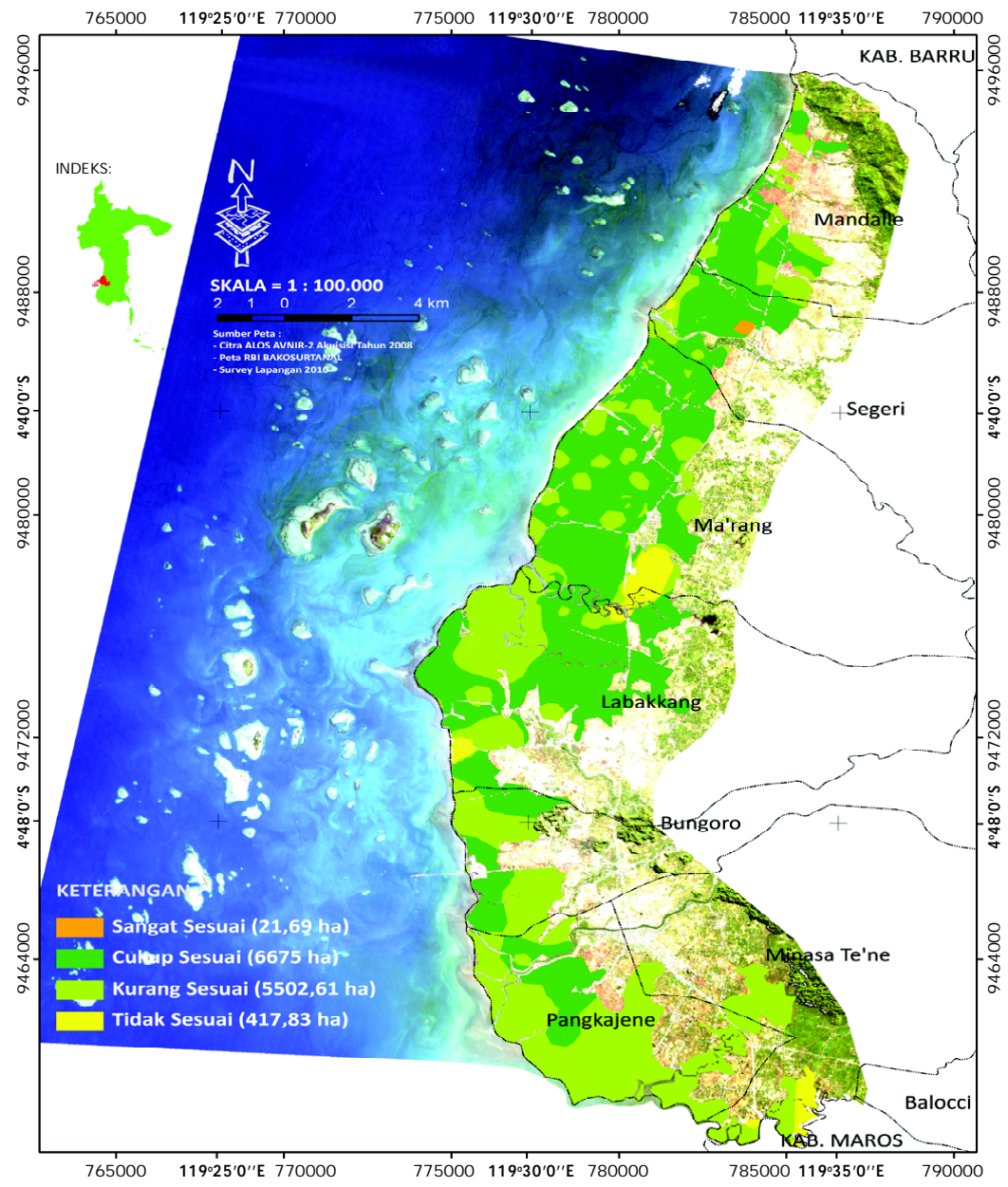

Gambar 2. Peta kesesuaian lahan budidaya tambak di Kabupaten Pangkep, Sulawesi Selatan

Figure 2. Land suitabiliy map for brackishwater pond culture in Pangkep Regency, South Sulawesi

\section{DAFTAR ACUAN}

Abdurachman, A. \& Suriadikarta, D.A. 2000 Pemanfaatan lahan rawa eks PLG Kalimantan Tengah untuk pengembangan pertanian berwawasan lingkungan. Badan Penelitian dan Pengembangan Pertanian, Departemen Pertanian, Jakarta. J. Litbang Pertanian, 19(3):77- 111.

Agus, F., Yusrial, \& Sutono. 2006. Penetapan tekstur tanah. Dalam Kurnia, U., Agus, F., Adimihardja, A., \&Dariah, A. (Eds.) Sifat Fisik Tanah dan Metode Analisisnya. Balai Besar Penelitian dan Pengembangan Sumberdaya Lahan Pertanian. Bogor, hlm. 43- 62.
Ahern, C.R., McElnea, A., \& Baker, D.E. 1998a. Acid neutralizing capacity methods. In Ahern, C.R., Blunden, B., \& Stone, Y. (Eds.) Acid Sulfate Soils Laboratory Methods Guidelines. Acid Sulfate Soil Management Advisory Committee, Wollongbar. NSW, p. 6.1-6.4.

Ahern, C.R., McElnea, A., \& Baker, D.E. 1998b. Peroxide oxidation combined acidity and sulfate. In Ahern, C.R., Blunden, B., \& Stone, Y. (Eds.) Acid Sulfate Soils Laboratory Methods Guidelines. Acid Sulfate Soil Management Advisory Committee, Wollongbar. NSW, p. 4.1-4.17. 
Ahmad, T., Mustafa, A., \& Hanafi, A. 1996. Konsep pengembangan desa pantai mendukung keberlanjutan produksi perikanan pesisir. Dalam Poernomo, A., Irianto, H.E. Nurhakim, S., Murniyati, \& Pratiwi, E. (Eds.) Prosiding Rapat Kerja Teknis Peningkatan Visi Sumberdaya Manusia Peneliti Perikanan Menyongsong Globalisasi IPTEK. Serpong, 19-20 November 1996. Badan Litbang Pertanian, Puslitbang Perikanan. Jakarta, hlm. 91- 106.

American Public Health Association (APHA). 2005. Standard methods for examination of water and wastewater. Twentieth edition APHA-AWWA- WEF. Washington, 1,185 pp.

Anonim. 2004. Laporan Tahunan Dinas Perikanan dan Kelautan Kabupaten Pangkep Tahun Anggaran 2004. Dinas Perikanan dan Kelautan Kabupaten Pangkep, $32 \mathrm{hlm}$.

Anonim. 2009. Kabupaten Pangkep Dalam Angka 2009. Pangkep Regency In Figures 2009. Kerja sama Badan Perencanaan Pembangunan Daerah dengan Badan Pusat Statistik Kabupaten Pangkep, $98 \mathrm{hlm}$.

Boyd, C.E. 1988. Water quality in warmwater fish ponds. Fourth Printing. Auburn University Agricultural Experiment Station. Alabama. USA, $359 \mathrm{pp}$.

Boyd, C.E. 1995. Bottom soil, sediment, and pond aquaculture. Chapman and Hall. New York, $46 \mathrm{pp}$.

Boyd, C.E., Wood, C.W., \& Thunjai, T. 2002. Aquaculture pond bottom soil quality management. Oregon State University. Corvallis. Oregon, $41 \mathrm{pp}$.

Dennis, M., Tammy, T., Baldwin, K., \& Kevin, F. 2004. Aquaculture development potential in Arizona: a GIS- based approach. World Aquaculture, 34(4): 32- 35.

Duivenbooden, N.V. 1995. Land use systems analysis as a tool in land use planning. 176 pp.

Effendi, H. 2003. Telaah kualitas air bagi pengelolaan sumber daya dan lingkungan perairan. Kanisius (Anggota IKAPI). Yogyakarta, $258 \mathrm{hlm}$.

Karthik, M., Suri, J., Saharan, N., \& Biradar, R.S. 2005. Brackhiswater aquaculture site selection in Palghar Taluk, Thane District of Maharashtra, India, using the techniques of remote sensing and Geographical Information System. Aquaculture Engineering, 32: 285- 302.

Kementerian Lingkungan Hidup. 2004. Kepu- tusan Menteri Negara Lingkungan Hidup, No. 51 tahun 2004, tanggal 8 April 2004 tentang Baku Mutu Air Laut. Kementerian Lingkungan Hidup. Jakarta, $11 \mathrm{hlm}$.

Menon, R.G. 1973. Soil and water analysis: a laboratory manual for the analysis of soil and water. Proyek Survai O.K.T. Sumatera Selatan, Palembang, $190 \mathrm{pp}$.

Moore, J.W. 1991. Inorganic contaminants of surface water. Springer Verlag. New York, $334 \mathrm{pp}$.

Mustafa, A., Tarunamulia, \& Hanafi, A. 2004. Karakteristik dan kesesuaian lahan budidaya tambak di Kecamatan Sampara Kabupaten Kendari Provinsi Sulawesi Tenggara. J. Pen. Perik. Indonesia, 10(2): 113.

Mustafa A., Utojo, Hasnawi, \& Rachmansyah. 2006. Validasi data luas lahan budidaya tambak di Kabupaten Maros dan Pangkep Provinsi Sulawesi Selatan dengan menggunakan teknologi penginderaan jauh dan sistem informasi geografis. Pusat Riset Perikanan Budidaya, Jakarta. J. Ris. Akuakultur, 3(1): 419-430.

Noor, M. 2004. Lahan rawa, sifat dan pengelolaan tanah bermasalah sulfat masam. Edisi ke- 1, cetakan pertama, PT Raja Grafindo Persada. Jakarta, $229 \mathrm{hlm}$.

Parson, T.R., Maita, Y., \&Lalli, C.M. 1989. A manual of chemical and biological methods for seawater analysis. Pergamon Press. Oxford, $173 \mathrm{pp}$.

Perez, O.M., Roos, L.G., Telfer, T.C., \& Del Campo Barquin, L.M. 2003. Water quality requirements for marine fish cage site selection in Tenerife (Canary Island): predictive modelling and analysis using GIS. Aquaculture, 224:51- 68 .

Poernomo, A. 1988. Pembuatan tambak di Indonesia. Seri Pengembangan No. 7, 1988. Departemen Pertanian, Badan Penelitian dan Pengembangan Pertanian, Balai Penelitian Perikanan Budidaya Pantai. Maros, 30 hlm.

Poernomo, A. 1989. Indonesia ought to learn from the failure of shrimp culture in Taiwan. Proc. Sci. Workshop on Research Support to the National Shrimp Industry Development Program. 1: 81- 161.

Poernomo, A. 1992. Pemilihan lokasi tambak udang berwawasan lingkungan, CRIFI Pub., $40 \mathrm{hlm}$.

Purwadhi, F.S.H. 1999. Sistem informasi geografis. Dalam Suharmanto, F., Tjinda, 
S., Yulmantoro, Arisdyo, I.L., Ginting, R., \& Effendi, A. (Eds.) Pengantar teknologi aplikasi penginderaan jauh satelit dan sistem informasi geografi. Lembaga Penerbangan dan Antariksa Nasional dengan Badan Pengkajian dan Penerapan Teknologi. Jakarta, hlm. 367- 494.

Reid, G.K. 1961. Ecology inland water estuaries. Rein Hald Published Co. New York, 37 pp.

Sulaeman, Suparto, \& Eviati. 2005. Petunjuk teknis analisis kimia tanah, tanaman, air, dan pupuk. Diedit Prasetyo, B.H., Santoso, D., \& Widowati, L.R. Balai Penelitian Tanah. Bogor, $136 \mathrm{hlm}$.

Sutrisyani \& Rohani, S. 2009. Panduan praktis analisis kualitas air payau. Diedit
Rachmansyah, Atmomarsono, M., \& Mustafa, A. Cetakan kedua. Pusat Riset Perikanan Budidaya. Jakarta, $55 \mathrm{hlm}$.

Utojo, Mustafa, A., Rachmansyah, \& Hasnawi. 2009. Penentuan lokasi pengembangan budi daya tambak berkelanjutan dengan aplikasi sistem informasi geografis di Kabupaten Lampung Selatan. J. Ris. Akuakultur, 4(3): 407- 423.

Widigdo, B. 2003. Permasalahan dalam budidaya udang dan solusinya. J. Ilmu-llmu Perairan dan Perikanan Indonesia, 10(1): 18- 23.

Yost, R.S., Uehara, G., \& Fox, R.L. 1982. Geostatistical analysis of soil chemical properties of large land areas. II. Kriging. Soil Science Society of American J., 46: 1,033-1,037. 